\title{
On the importance of attempting to know the causes of things: a reply to Sunstein
}

\author{
Adam Oliver \\ Department of Social Policy, London School of Economics and Political Science, London, UK \\ E-mail: a.j.oliver@lse.ac.uk
}

(Received 25 January 2022; accepted 25 January 2022)

\begin{abstract}
Cass Sunstein's contention that evolutionary explanations for behavioural economic phenomena are of limited relevance to public policy - and his support for soft paternalism rests on his view that policymakers ought to be pursuing increases in some overarching social planning conception of welfare. In this reply to Sunstein, I argue that people have differing and multifarious desires in life, with the social planner's conception of welfare being, at best, perhaps only a partial consideration for most people. The phenomena that behavioural economists and psychologists have empirically observed may well facilitate people in the pursuit of their own desires in life. Consequently, paternalistic manipulation or coercion to save people from themselves is questionable in the behavioural public policy space, but government intervention is warranted when one party implicitly or explicitly uses these phenomena to exploit others.
\end{abstract}

Keywords: biases; budge; evolution; nudge; welfare

The motto of my home institution is rerum cognoscere causas - 'to know the causes of things'. This motto has for a long time struck me as a little odd, particularly in relation to the social sciences, for can we ever definitively know the causes of things? We can, and I think should, strive to better understand the causes of things, but perhaps that would make for a clumsy motto. That clumsy phrase aside, I still contend that we ought to strive to better understand the causes of the phenomena that most behavioural economists consider to be biasing influences. By doing so, although inevitably to a degree speculative, we might conclude that they may have evolved for good reasons, and are not, therefore, biasing influences at all.

\section{Whither welfare maximisation}

Sunstein (2022) does not (of course!) agree. In reflecting on my short article that questioned whether the postulates of prospect theory really explain the observations of that theory's most distinctive implication (i.e., the reflection effect; see Oliver, 2021b), he downplays the policy import of possible evolutionary explanations for the behavioural 
phenomena that have been uncovered by behavioural economists and psychologists over recent decades. At the heart of Sunstein's argument is the assumption, which is taken as self-evident, that policymakers ought to aim to improve some overarching concept of welfare or utility or well-being of the citizens they serve, with the criteria for that concept set by the social planner. Since the behavioural 'biases', irrespective of how or why they evolved, move many people away from those criteria, there is a paternalistic justification - for Sunstein, the familiar libertarian paternalistic justification - for the policymaker to intervene in individual choice, actions and behaviours.

However, assuming that people generally want to maximise a third person's view of what their own lifetime welfare or utility ought to be is, using Sugden's (2018) pejorative intention, 'a view from nowhere'. Some people might indeed wish to maximise their own welfare as such, but others are likely to have different personal goals for themselves, and with 'processes' rather than a pure concern with 'outcomes' mattering substantively to many of us. The behavioural phenomena that have been empirically unearthed over recent decades may have evolved to facilitate people in the pursuit of their personal goals (see Oliver, 2021a). If people have differing and multifarious desires for what they wish to do with their lives, the imposition of some uniform standard of welfare upon all is erroneous, and therefore the behavioural phenomena that steer people away from that uniform standard are not necessarily in need of correction. With respect to people's private lives (assuming that they are not imposing substantive harms on others), I would argue that the policymaker's role is thus to focus on producing the general conditions for citizens to pursue their own desires in life. That would leave people free to pursue some lifetime concept of outcomes-based welfare or utility if they wish, but would not see them manipulated or even coerced towards that goal if their desires lie elsewhere.

Incidentally, no one, as far as I know, is arguing that everyone is predominantly driven by the same evolutionary force. Some people are present-oriented, others are more future-oriented; some are pessimistic, some optimistic; some risk-averse, others more risk-seeking; some driven by outcomes, others more by processes; etc. However, different tendencies may be more or less drawn out within most people depending on the context that they face because the context will determine the relative advantageousness of each tendency. For example, when faced with extreme scarcity rather than relative abundance, more people may be more risk-seeking than they were otherwise, because in such circumstances that will increase their likelihood of survival. Even in those circumstances, one might observe risk aversion in people who are facing very challenging financial circumstances (although perhaps to a lesser degree than when they have abundant resources), but if more people are more likely to be risk-seeking when facing extreme hardship, then when studying a population, general behavioural patterns will be consistent with - if not necessarily explained by - prospect theory's reflection effect.

\section{Whither government intervention}

I should repeat, for emphasis, that my contention that policymakers limit themselves to providing the general conditions that facilitate people in the pursuit of their own conceptions of a flourishing life applies only to those circumstances where 
governments might otherwise resort to paternalism. In the spirit of von Humboldt (1791-92/1993), Mill (1859/1969) and other like-minded liberals, where people are imposing behavioural-informed harms on others, as opposed to supposedly behavioural-informed harms on themselves, there is a potential justification for more forceful state intervention. Many appear to believe that the distinction between paternalistic and non-paternalistic policy - between internality and externality concerns - is a deeply uninteresting question, but I am of the view that it is perhaps the most profound consideration for the future development of behavioural public policy. ${ }^{1}$

Part of Sunstein's critique of using evolutionary explanations to inform policy is that such explanations might justify in-group favouritism, certain male attitudes towards women, and cruelty towards non-human animals. However, all of these examples entail harms imposed by one party on another, and thus in an evolutionary-respecting liberal framework state intervention against these actions and attitudes, assuming that the harms are considered substantive (which, in these examples, seems likely), would be entirely justifiable. Moreover, attempting to understand why these actions and attitudes evolved would still be useful, as such knowledge may facilitate the design of appropriate and effective regulation.

For me, the behavioural phenomena that Sunstein mentions - that is, present bias, optimistic overconfidence, and the availability heuristic - have relevance to public policymaking if they are being used, implicitly or explicitly, by one party to exploit in some way another party. This will typically occur in the manipulation of the exchange relationship between two parties and undermines the very notion of fairness in exchange. We could of course adopt the principle of caveat emptor - let the 'buyer' beware - but it is very difficult for people always to avoid by themselves being manipulated by others in these ways, because the behavioural phenomena are ingrained and usually almost unquestioned parts of their own psyches. Therefore, when the harms imposed upon them are substantive, there are good grounds for policymakers to offer a helping hand, in the form of behavioural-informed regulations against harms, an approach that I have elsewhere labelled 'budge' (e.g., see Oliver, 2013). ${ }^{2}$

\section{Whither evolution and the reflection effect}

In response to my suggestion that people may be implicitly risk-averse in the face of abundance and risk-seeking in the face of extreme scarcity (Oliver, 2021b),

\footnotetext{
${ }^{1}$ An element of 'nudge imperialism' has taken root in the field of behavioural public policy over the past decade, where every conceivable behavioural intervention is now defined by many as a nudge of some sort. However, nudges are applications of libertarian paternalism; if an intervention is externality-focussed, it is not a nudge at all. The relaxation in the use of terminology has created much confusion.

${ }^{2}$ For example, an overt regulation against behavioural-informed tactics by the gambling industry that manipulate people to gamble more than they otherwise would is a budge. A soft paternalistic covert measure that aims to reduce gambling activities undertaken by people, even if they are not being manipulated by the industry to gamble, is a nudge. I prefer the former than the latter approach to behavioural public policy, supplemented with explicit government-sponsored education and information on the harms to self that excessive gambling can cause.
} 
Sunstein (2022) states that it would seem to follow that wealthy people will be risk-averse and poor people will be risk-seeking'. In response to this, I reply, 'not necessarily', and for two reasons. First, as alluded to above, there is still likely to be a large degree of individual heterogeneity in risk preferences across those who face similar financial circumstances - it is just that for those facing abundance compared to those facing extreme scarcity, the general tendency will be for greater risk-seeking in the latter than in the former. Second, even within what might be defined as a class of financial circumstances, these general tendencies will be sensitive to the severity of the situation that people find themselves in. For example, some people who may be classified as poor may still, in general, find it most fruitful to navigate their way through life by being quite risk-averse - that is, the risk-averse strategy meets their needs. But for other poor people who face more severe circumstances where the risk-averse option inevitably spells disaster, the risk-seeking strategy may offer the only hope of survival. ${ }^{3}$

Sunstein makes other points that I contest. For example, in implicitly suggesting that risk aversion is invariably erroneous, he argues that if you keep choosing $\$ 100$ over an $80 \%$ chance to win $\$ 140$ (and a $20 \%$ chance to win $\$ 0$ ), you will lose a lot of money over your lifetime. That may be true if you are in a position where you face such a repeated game, but many 'games' in life are not repeated, or not repeated much, and even when they are, it might be the case that people are dependent on an outcome in the short term (e.g., some people might need $\$ 100$ to get through the next week). The choice, using the above example, in one-shot or 'time-dependent' games is not, therefore, between $\$ 100$ and an expectation of $\$ 112$; it is between $\$ 100$ and $\$ 140$ or nothing, and many might reasonably, and I dare say rationally, think that the option that might produce nothing is too painful to bear. ${ }^{4}$

Sunstein (2022) concludes by stating that 'Even when evolutionary explanations for behavioural findings are plausible, they do not establish that people are acting rationally, that they are not making mistakes, and that decisions are promoting their welfare.' I conclude by stating that if we accept that promoting some overarching standard of welfare or utility is not necessarily what many people want to achieve in their lives - that people have multifarious and varied desires - then the behavioural findings, which presumably evolved for a reason (or reasons), might often be consistent with an 'inclusive' sense of rationality, and might not be biasing influences at all. Sunstein is right, I think, when he contends that evolutionary explanations are (sometimes excessively) speculative, but the view that people generally want and ought to pursue some universal standard of welfare is speculative, and I think incorrect, also.

\footnotetext{
${ }^{3}$ Similar arguments can be made with respect to the wealthy. For example, some wealthy people - to use Sunstein's example, an Elon Musk, say - might have such an abundance of resources that experiencing the worst outcome in a risk-seeking strategy is, for them, inconsequential. So, they might then take risks just for the fun of it. Incidentally, as I alluded to in my original article, varying the magnitude of the outcomes that people face may change their implicit perceptions of whether they are facing extreme abundance or abundance or scarcity or extreme scarcity, and may lead to risk preference patterns that do not mirror those predicted by prospect theory's reflection effect. In short, there may be circumstances where the evolutionary postulates that I am suggesting do not necessarily marry with the predictions of prospect theory, which would be interesting to test.

${ }^{4}$ Samuelson (1963) presented a related discussion.
} 


\section{References}

Mill, J. S. (1859/1969), 'On liberty', in On liberty and utilitarianism, Oxford: Oxford University Press, 1-110. Oliver, A. (2013), 'From nudging to budging: Using behavioural economics to inform public sector policy', Journal of Social Policy, 42(4): 685-700.

Oliver, A. (2021a), 'An unhappy pursuit of happiness', LSE Public Policy Review, 1(3): 3.

Oliver, A. (2021b), 'Reflecting on reflection: Prospect theory, our behaviours, and our environment', Behavioural Public Policy, 1-11. doi:10.1017/bpp.2021.31.

Samuelson, P. (1963), 'Risk and uncertainty: A fallacy of large numbers', Scienta, 98(4): 108-13.

Sugden, R. (2018), The community of advantage: A behavioural defence of the liberal tradition of economics. Oxford: Oxford University Press.

Sunstein C. (2022), 'On the limited policy relevance of evolutionary explanations', Behavioural Public Policy, 1-7. doi:10.1017/bpp.2022.4.

von Humboldt, W. (1791-92/1993), The limits of state action. Indianapolis: The Liberty Fund.

Cite this article: Oliver A (2022). On the importance of attempting to know the causes of things: a reply to Sunstein. Behavioural Public Policy 1-5. https://doi.org/10.1017/bpp.2022.5 